\title{
Prevalence and determinants of low social support during pregnancy among Australian women: a community-based cross-sectional study
}

\author{
Asres Bedaso ${ }^{1,2^{*}} \mathbb{C}$, Jon Adams ${ }^{2}$, Wenbo Peng ${ }^{2}$ and David Sibbritt ${ }^{2}$
}

\begin{abstract}
Background: Pregnancy is a time for women in which the need for social support is crucial. Social support reduces stressors and improves the emotional and physical well-being of pregnant women. Women receiving low social support during pregnancy are at risk of substances use, developing mental illness, and adverse birth outcomes. The current study aims to determine the prevalence and determinants of low social support during pregnancy among Australian women.
\end{abstract}

Methods: Data were obtained from the 1973-1978 cohort of Australian Longitudinal Study on Women's Health (ALSWH) and those who report being pregnant $(n=493)$ were included in the current analyses. Social support was assessed using Medical Outcomes Study Social Support index (MOSS). A logistic regression model was applied to identify determinants of low social support, separately for each MOSS domain.

Result: The study found that $7.1 \%(n=35)$ of pregnant women reported low social support. Significant determinants of low emotional support were non-partnered ( $A O R=4.4,95 \% \mathrm{Cl}: 1.27,14.99)$, difficulty managing on available income ( $\mathrm{AOR}=3.1,95 \% \mathrm{Cl}: 1.18,8.32$ ), experiencing depressive symptoms ( $\mathrm{AOR}=8.5,95 \% \mathrm{Cl}: 3.29,22.27$ ) and anxiety symptoms ( $A O R=2.9,95 \% \mathrm{Cl}: 1.26,7.03)$. Significant determinants of low affectionate support were suffering from depressive symptoms ( $\mathrm{AOR}=5.3,95 \% \mathrm{Cl}: 1.59,17.99)$, having anxiety symptoms (AOR: 6.9, 95\% Cl: 2.21, 22.11) and being moderately/very stressed (AOR: $3,95 \% \mathrm{Cl}: 1.17,7.89$ ). Significant determinants of low tangible support were difficulty managing available income ( $\mathrm{AOR}=3,95 \% \mathrm{Cl}: 1.29,6.95)$, and being depressed ( $\mathrm{AOR}=2.8,95 \% \mathrm{Cl}: 1.48,5.34$ ).

Conclusion: The study revealed that $7.1 \%$ of pregnant women reported low social support. Having a mental health problems, being stressed, being from low socio-economic status and being non-partnered were significant determinants of low social support during pregnancy. Maternal health professionals and policymakers can use this information to screen pregnant women at risk of receiving low social support and improve the level of support being provided.

\footnotetext{
*Correspondence: asresbedaso@gmail.com

${ }^{1}$ College of Medicine and Health Sciences, Faculty of Health, School

of Nursing, Hawassa University, Hawassa, Ethiopia

Full list of author information is available at the end of the article
}

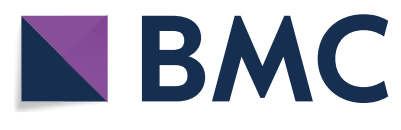

(c) The Author(s) 2021. Open Access This article is licensed under a Creative Commons Attribution 4.0 International License, which permits use, sharing, adaptation, distribution and reproduction in any medium or format, as long as you give appropriate credit to the original author(s) and the source, provide a link to the Creative Commons licence, and indicate if changes were made. The images or other third party material in this article are included in the article's Creative Commons licence, unless indicated otherwise in a credit line to the material. If material is not included in the article's Creative Commons licence and your intended use is not permitted by statutory regulation or exceeds the permitted use, you will need to obtain permission directly from the copyright holder. To view a copy of this licence, visit http://creativecommons.org/licenses/by/4.0/. The Creative Commons Public Domain Dedication waiver (http://creativeco mmons.org/publicdomain/zero/1.0/) applies to the data made available in this article, unless otherwise stated in a credit line to the data. 


\begin{abstract}
Plain Language Summary
Providing strong social support improves emotional and physical well-being, strengthens social relationships, promotes health, and enhances the stress coping ability of pregnant women. However, pregnant women receiving low social support are at risk of substances use, developing mental illness, and adverse birth outcomes. The current study aims to determine the prevalence and determinants of low social support during pregnancy among Australian women. Data were obtained from Survey 6 of the 1973-1978 cohort of the Australian Longitudinal Study on Women's Health (ALSWH) $(n=493$, pregnant women aged 34-39 years). This cohort is one of ALSWH ongoing communitybased study focusing on the health of women in Australia. Social support provided for a pregnant woman was the outcome variable, assessed using the 19-item Medical Outcomes Study Social Support index (MOSS). The prevalence of low social support in each domain was calculated for each of the independent variables. A logistic regression model, using a backward stepwise elimination approach, was employed to identify determinants of low social support. In the final model, the strength of association measured by adjusted odds ratios (AOR) with $95 \%$ confidence intervals. The significance level was set at $p<0.05$. From the total participant pregnant women, $7.1 \%$ of them reported low social support. Significant determinants of low social support among pregnant Australian women were, having a mental illness, being stressed and/or being from low socio-economic status and being non-partnered. Maternal health professionals can use this information to screen pregnant women at risk of receiving low social support as well as develop policy to help enhance the social support being given and the psychological wellbeing being of pregnant women.
\end{abstract}

Keywords: Low social support, Emotional support, Affectionate support, Tangible support, Mental health, Women, Pregnancy

\section{Background}

Pregnancy is an important but emotionally sensitive time for most women and it is also accompanied by changes in, physical appearance, role and lifestyles [1, 2]. Such changes may have an impact on the attitude, decision making and behaviour of the pregnant mother in undertaking the social responsibility that comes with pregnancy and motherhood [3]. These changes during pregnancy may be exacerbated by financial problems, relationship issues and lack of social support [4-6]. Thus, to tackle these challenges the need for social support during pregnancy is vital [7].

Social support is defined as the provision of emotional (e.g. caring), or informational (e.g. notifying someone of important information) support, instrumental (e.g. helping with housekeeping), tangible (e.g. practical support like financial aid), and/or psychological support for somebody by the social network of family members, friends, and community members [8]. It is an assistance from one individual or a social network that is given to another individual, which produces an instant or later positive response in the recipient [9]. Social support is assumed to influence through two potential mechanisms (i.e. main effects and buffering mechanism) [10-12]. As the main effect, social support and social network provide a sense of belonging and stability which result in improved self-esteem and reduce the risk of stress and mental illness [12]. Social support can act as a buffer by providing access to additional resources to enhance suitable coping mechanism for pregnant women to deal with stressful events [10, 12].

Providing strong social support improves emotional and physical well-being [13], strengthens social relationships, promotes health [14], and enhances the ability of pregnant women to cope with stress $[15,16]$. Also, social support can reduce functional impairment among individuals with depressive symptoms, and increase the likelihood of recovery, thereby improving the overall quality of life (QOL) $[17,18]$. It has been suggested that social support interventions and social participation are effective in preventing prenatal and neonatal adverse birth outcomes [19, 20]. Furthermore, social support can improve self-confidence, increase resistance to infections, and contribute to a healthier lifestyle [21, 22]. The vast bulk of research examining the relationship between social support and pregnancy outcomes over the past thirty years have shown individuals who receive good social support have greater longevity than those with poor social support [23].

Previous studies have shown that low social support is a risk factor for depression during pregnancy and postbirth [24-26], as well as a greater risk of giving birth to an underweight infant [27]. There appears to be a significant association between a lack of social support and drinking alcohol, smoking tobacco and illicit drugs use during pregnancy [28-30] and pregnant women who report anxiety disorder, who smoke tobacco, who live without a partner, who have an unplanned pregnancy and/or who have a low socio-economic status also report low social 
support [31]. Furthermore, a women's level of education and length of relationship with their partner are also important determinants of social support during pregnancy [32].

Despite all this evidence, no study has addressed the prevalence and determinants of low social support during pregnancy among Australian women. Therefore, the purpose of the current study intended to fill this research gap by examining the prevalence and determinants of low social support during pregnancy amongst a sample of Australian pregnant women.

\section{Methods and materials}

\section{Population, sampling and data collection}

Data were obtained from the Australian Longitudinal Study on Women's Health (ALSWH) [33, 34]. ALSWH was established in 1996 with the recruitment of 40,000 women in three different age cohorts (women born between 1973-1978, 1946-1951 and 1921-1926). The ALSWH project is designed to observe changes in women's health through follow-up, provide information that will elucidate cause-and-effect relationships and examine the effects of changes in policy and practice.

ALSWH study participants were selected randomly (with over-sampling of women living in rural and remote areas, who were sampled at twice the rate of women in urban areas) using the national health insurance database (now Medicare Australia). Information from participants for the 1873-1878 cohort was gathered via mailed surveys on a three-year interval. The age of participating women of the 1973-1978 cohort was between 18 and 23 years when recruited in 1996 and were broadly representative of the population of similar age Australian women at that time [35]. Details about the ALSWH project have been published elsewhere [33, 34]. The sample for this study was drawn from Survey 6 of the 1973-1978 cohort. From the 8010 women who completed Survey 6 (aged 34-39 years), those who report being pregnant $(\mathrm{n}=493)$ were included in the current analysis.

\section{Variables and measurement}

Social support provided for a pregnant woman was the outcome variable, assessed using the Medical Outcomes Study Social Support index (MOSS) [36]. MOSS has an overall index of 19 items and 4 functional support subscales: emotional/informational support (involves caring, love and empathy) (8 items); tangible support (the provision of material aid or behavioral assistance) (4 items); and affectionate support/positive social interaction (involving expressions of love and affection/the availability of other persons to do fun things) (7 items). Each of the 19 items has a 5-point Likert response (ranging from: 'none of the time' $=1$ to 'all of the time' $=5$ ) assessing the availability of support. For the purpose of the current analysis, each domain of social support was categorized into high ("all of the time" and "most of the time") and low ("a little of the time/none" and "some of the time") social support [36].

Study participants were requested to specify their marital status as either "married," "never married," "de facto," "separated," "divorced," or "widowed." For the current analysis, groups were re-categorized into either "partnered" (married or de facto) or "non-partnered" (single, divorced, separated, or widowed). Postcode of residence was used to categorise respondents as living in either "major cities of Australia", "inner regional Australia", "outer regional Australia" or "remote or very remote Australia" [37]. Income stress was measured via how respondents reported ability to manage on available income, with response options: "impossible", "difficult all of the time", "difficult some of the time", "not too bad", or "easy". For the purposes of analyses, these options were collapsed into 2 categories, "impossible or difficult all or some of the time" and "not too bad or easy".

The respondents were questioned about their alcohol consumption. Based on their responses, the women were then categorised as being either a "non-drinker" or a "drinker" of alcohol. Similarly, based on their response to a question regarding cigarette smoking, the women were categorised as being either a "non-smoker" or a "current smoker". To assess illicit drug use, women were provided with a list of drugs and asked if they had used any of them during the past 12 months. The list of drugs included Marijuana; Amphetamines; LSD; Hallucinogens; Tranquillizers; Cocaine; Ecstasy/designer drugs; Inhalants; Heroin; Barbiturates; and Steroids. Based on their responses, the women were classified as being either a "non-user" or a "user" of illicit drug.

The level of stress in the last 12 months among study participants was assessed using the Perceived Stress Questionnaire, which has been developed and validated for the ALSWH study [38]. The tool examined the level of perceived stress in specific areas of life, including study, relationships and own health. An overall mean stress score was determined, which ranges from 0 (no stress) to 4 (extreme stress). The Perceived Stress Questionnaire has good internal reliability $(\alpha=0.75)[39,40]$.

Depression was assessed using the 10-item Center for Epidemiological Studies Depression (CES-D-10) scale, with a possible range of $0-30$, and Cronbach's alpha 0.79 . Cutoff point $\geq 10$ from the total score indicates the presence of depressive symptoms [41]. CES-D-10 has been used to examine depressive symptoms during pregnancy with good reliability and validity [42-46]. The anxiety symptoms among pregnant mothers were assessed using the 9-item (yes/no) Anxiety subscale of the Goldberg 
Anxiety and Depression scale (GADS). A score of GADS greater than 6 indicates the presence of anxiety symptoms and has good reliability with Cronbach's alpha of 0.77 [47].

\section{Data analysis}

Data were analysed using SPSS version 22. Chi-square tests were used to test for crude associations between domains of social support and socio-demographic, mental health, and lifestyle behaviour related factors. Independent sample t-test analyses were performed to examine the difference in the mean age of pregnant women for each domain of social support. The prevalence of low social support in each domain was calculated for each of the independent variables. During the bivariate analyses variables with a p-value less than 0.25 entered into a multiple logistic regression model. In the final model, significant determinants of low social support were identified using a backward stepwise elimination approach. The strength of association measured by adjusted odds ratios (AOR) with 95\% confidence intervals. The significance level was set at $\mathrm{p}<0.05$. The model fitness test was conducted using the Hosmer and Lemeshow goodness of fit test [48].

\section{Ethics approval and consent to participate}

The ALSWH has been granted ethics clearance by the human research Ethics committee of the University of Newcastle (\#H-076-0795) and the University of Queensland (\#2004000224). Study participants were involved voluntarily and provided written informed consent. The confidentiality of study participants' information is firmly monitored by ALSWH staff. Approval letter for the current study was obtained from the Human Research Ethics Committee of the University of Technology Sydney (ETH20-5306).

\section{Result}

The mean age of participating women was 36.3 (standard deviation $[\mathrm{SD}]=1.42$ ). The majority of participants (95.12\%) were married/De facto, while $65 \%$ attained a university degree. The majority of these women (61.1\%) lived in major cities and $44.6 \%$ responded to having little or no difficulty in managing available income. The majority of the women (42\%) were in the last trimester of their pregnancy, while $37.5 \%$ and $20.5 \%$ were in the second and first trimester respectively (Table 1 ). The overall prevalence of low social support among pregnant women was $7.1 \%(n=35)(95 \%$ CI: 4.83, 9.39). Considering the specific domains of social support, the prevalence of low emotional support, low affectionate support and low tangible support in the current study was found to be $7.9 \%$, $4.9 \%$, and $10.9 \%$, respectively. It was found that $25.1 \%$ of
Table 1 Demographic characteristics of participating pregnant women $(n=493)$

\begin{tabular}{|c|c|c|}
\hline Demographic characteristics & Number & Percent \\
\hline \multicolumn{3}{|l|}{ Residence } \\
\hline Major cities & 286 & 61.1 \\
\hline Inner regional & 103 & 22 \\
\hline Outer regional & 66 & 14.1 \\
\hline Remote/very remote ${ }^{\mathrm{a}}$ & 13 & 2.8 \\
\hline \multicolumn{3}{|l|}{ Occupation } \\
\hline Manager/professional/Assoc. Professional & 294 & 59.8 \\
\hline No paid job & 100 & 20.4 \\
\hline Others $^{b}$ & 97 & 19.8 \\
\hline \multicolumn{3}{|l|}{ Marital status } \\
\hline Married/De facto (opposite sex) & 466 & 95.12 \\
\hline Never married & 12 & 2.44 \\
\hline Divorced/separated ${ }^{c}$ & 12 & 2.44 \\
\hline \multicolumn{3}{|l|}{ Highest qualification achieved } \\
\hline University & 319 & 65 \\
\hline Certificate/diploma & 104 & 21.2 \\
\hline Year 12 or equivalent & 43 & 8.8 \\
\hline Others $^{d}$ & 25 & 5 \\
\hline \multicolumn{3}{|l|}{ Pregnancy month } \\
\hline$<3$ month & 101 & 20.5 \\
\hline $3-6$ month & 185 & 37.5 \\
\hline$>6$ month & 207 & 42 \\
\hline \multicolumn{3}{|l|}{ Able to manage on income available } \\
\hline Difficult all the time/impossible ${ }^{\mathrm{e}}$ & 43 & 8.8 \\
\hline Difficult some of the time & 118 & 24 \\
\hline Not too bad & 219 & 44.6 \\
\hline It is easy & 111 & 22.6 \\
\hline
\end{tabular}

${ }^{\text {a Remote }}(n=6)$, Very remote $(n=7)$

${ }^{b}$ Others (Tradesperson or related worker $(n=7)$, Advanced clerical or service worker $(n=33)$, Intermediate clerical, sales/service worker $(n=38)$, Intermediate production or transport worker $(n=1)$, Elementary clerical, sales or service worker $(n=11)$, Labourer or related worker $(n=7)$ )

' Divorced (6), Separated (6)

d Others ( $n$ o formal education $(n=2)$, Year 10 or equivalent $(n=15)$, Trade/ apprenticeship $(n=8))$

e Impossible $(n=8)$, Difficult all the time $(n=35)$

the women reported depressive and $20.9 \%$ reported anxiety symptoms.

The bivariate associations between demographic factors and domains of social support during pregnancy are shown in Table 2. Women with low emotional support were more likely to be non-partnered $(\mathrm{p}<0.001)$ and report that their ability to manage on available income was impossible/difficult all of the time $(\mathrm{p}<0.001)$. Similarly, women with low affectionate support were more likely to be non-partnered and found it difficult all of the time/impossible to manage on their available income $(\mathrm{p}<0.001)$. Also, women with low tangible support were 
Table 2 Demographic factors associated with low social support domains during pregnancy among Australian women ( $\mathrm{n}=493$ )

\begin{tabular}{|c|c|c|c|c|c|c|c|c|c|}
\hline \multirow{3}{*}{$\begin{array}{l}\text { Demographic } \\
\text { characteristics }\end{array}$} & \multicolumn{2}{|c|}{ Emotional support } & \multirow[t]{3}{*}{ p-value } & \multicolumn{2}{|c|}{ Affectionate support } & \multirow[t]{3}{*}{ p-value } & \multicolumn{2}{|c|}{ Tangible support } & \multirow[t]{3}{*}{$p$-value } \\
\hline & Low $(n=39)$ & High $(n=453)$ & & $\operatorname{Low}(n=24)$ & High $(n=467)$ & & $\operatorname{Low}(n=52)$ & High $(n=439)$ & \\
\hline & n (\%) & n (\%) & & n (\%) & n (\%) & & n (\%) & n (\%) & \\
\hline \multicolumn{10}{|l|}{ Residence } \\
\hline Major cities & $17(43.5)$ & $269(59.4)$ & 0.093 & $11(45.8)$ & $274(58.6)$ & 0.399 & $27(52)$ & $259(59)$ & 0.42 \\
\hline Inner regional & $12(30.7)$ & $90(19.8)$ & & $7(29.2)$ & $95(20.4)$ & & $14(27)$ & $88(20)$ & \\
\hline $\begin{array}{l}\text { Outer regional/ } \\
\text { remote/very remote }\end{array}$ & $9(23.07)$ & $70(15.4)$ & & $5(25)$ & $74(16)$ & & $10(19)$ & $68(16)$ & \\
\hline \multicolumn{10}{|l|}{ Marital status } \\
\hline Partnered & $32(82)$ & $436(96.2)$ & $<0.001$ & 20 (83.3) & $447(96)$ & 0.006 & $45(86.5)$ & $422(96)$ & 0.002 \\
\hline Non-partnered & $7(18)$ & $17(3.8)$ & & $4(16.7)$ & $20(4)$ & & $7(13.5)$ & $17(4)$ & \\
\hline \multicolumn{10}{|l|}{$\begin{array}{l}\text { Highest qualification } \\
\text { achieved }\end{array}$} \\
\hline University & $20(51.3)$ & $299(66)$ & 0.065 & $13(54.2)$ & $305(65.5)$ & 0.209 & $33(63.5$ & $285(65)$ & 0.21 \\
\hline $\begin{array}{l}\text { Certificate/diploma or } \\
\text { trade/apprentice- } \\
\text { ship }\end{array}$ & $10(25.6)$ & $102(22.5)$ & & $9(37.5)$ & $103(22.1)$ & & $9(17.3)$ & $103(23.6)$ & \\
\hline School only & $9(23.1)$ & $51(11.5)$ & & $2(8.3)$ & $58(12.4)$ & & $10(19.2)$ & $50(11.4)$ & \\
\hline \multicolumn{10}{|l|}{ Pregnancy months } \\
\hline$<3$ month & $6(15.4)$ & 95 (20.9) & 0.62 & $4(16.7)$ & $97(20.7)$ & 0.96 & $8(15.4)$ & $93(21.2)$ & 0.246 \\
\hline $3-6$ month & $17(43.6)$ & $168(37)$ & & $11(45.8)$ & $174(37.3)$ & & $25(48.1)$ & $160(36.4)$ & \\
\hline$>6$ month & $16(41)$ & $190(41.9)$ & & $9(37.5)$ & $196(42)$ & & $19(36.5)$ & $186(42.4)$ & \\
\hline \multicolumn{10}{|l|}{$\begin{array}{l}\text { Able to manage on } \\
\text { income available }\end{array}$} \\
\hline $\begin{array}{l}\text { Impossible/difficult all } \\
\text { of the time }\end{array}$ & 13 (33.3) & $30(6.6)$ & $<0.001$ & $8(33.3)$ & $35(7.5)$ & $<0.001$ & $13(25)$ & $30(6.8)$ & $<0.001$ \\
\hline $\begin{array}{l}\text { Difficult some of the } \\
\text { time }\end{array}$ & $9(23.1)$ & $109(24.1)$ & & $3(12.5)$ & $115(24.6)$ & & $14(26.9)$ & $103(23.5)$ & \\
\hline \multirow[t]{2}{*}{ It is easy/not bad } & 17 (43.6) & $313(69.2)$ & & $13(54.2)$ & 317 (67.9) & & $25(48.1)$ & 305 (69.6) & \\
\hline & Mean (SD) & Mean (SD) & p-value & Mean (SD) & Mean (SD) & $p$-value & Mean (SD) & Mean (SD) & p-value \\
\hline Age & $36.78(1.5)$ & $36.3(1.40)$ & 0.035 & $36.9(1.42)$ & $36.28(1.4)$ & 0.021 & $36.5(1.44)$ & $36.3(1.41)$ & 0.234 \\
\hline
\end{tabular}

p-value was based on chi-square test and t-test statistics

more likely to find it difficult all of the time/impossible to manage on their available income $(\mathrm{p}<0.001)$ and were more likely to be non-partnered $(\mathrm{p}=0.002)$. There was a significant mean age difference between participants with low/high emotional support $(\mathrm{p}=0.021)$, and low/ high affectionate support $(\mathrm{p}=0.021)$.

Table 3 shows the bivariate associations between mental health and lifestyle behaviour related factors and domains of social support. Women with low emotional support more likely to report being depressed $(\mathrm{p}<0.001)$, anxiety $(\mathrm{p}<0.001)$, diagnosed or treated for depression in the past 3 years $(\mathrm{p}<0.001)$, diagnosed or treated for anxiety in the past 3 years $(\mathrm{p}=0.021)$ and being moderately/very stressed $(p<0.001)$ during pregnancy compared with participants getting high emotional support. Similarly, women with low affectionate support were more likely to report being depressed $(p<0.001)$, anxiety $(\mathrm{p}<0.001)$, diagnosed or treated for anxiety in the past 3 years $(p=0.042)$ and being moderately/very stressed $(\mathrm{p}<0.001)$. In addition, women with low tangible support were more likely to report being depressed $(\mathrm{p}<0.001)$, anxiety $(\mathrm{p}=0.001)$, diagnosed or treated for depression in the past 3 years $(p=0.002)$, diagnosed or treated for anxiety in the past 3 years $(\mathrm{p}=0.007)$ and being moderately/very stressed $(\mathrm{p}=0.002)$.

The significant factors associated with low social support during pregnancy are presented in Table 4. After adjusting for confounding variables, multiple logistic regression found that non-partnered pregnant women $(\mathrm{AOR}=4.4$; 95\% CI: 1.27, 14.99; $\mathrm{p}=0.019)$, difficulty all the time/impossible to manage on available income $(\mathrm{AOR}=3.1 ; 95 \% \mathrm{CI}$ : $1.18,8.32 ; \mathrm{p}=0.023$ ), suffering from depressive symptoms $(\mathrm{AOR}=8.5,95 \% \mathrm{CI}: 3.29,22.27, \mathrm{p}<0.001)$ and having anxiety symptoms $(\mathrm{AOR}=2.9 ; 95 \% \mathrm{CI}: 1.26,7.03 ; \mathrm{p}=0.013)$ 
Table 3 Mental health and lifestyle behaviour related factors associated with low social support during pregnancy among Australian women $(n=493)$

\begin{tabular}{|c|c|c|c|c|c|c|c|c|c|}
\hline \multirow[t]{3}{*}{ Variables } & \multicolumn{2}{|c|}{ Emotional support } & \multirow[t]{3}{*}{$p$-value } & \multicolumn{2}{|c|}{ Affectionate support } & \multirow[t]{3}{*}{$p$-value } & \multicolumn{2}{|c|}{ Tangible support } & \multirow[t]{3}{*}{ p-value } \\
\hline & Low $(n=39)$ & High $(n=453)$ & & $\operatorname{Low}(n=24)$ & High $(n=467)$ & & $\operatorname{Low}(n=52)$ & High $(n=439)$ & \\
\hline & n (\%) & n (\%) & & n (\%) & n (\%) & & n (\%) & n (\%) & \\
\hline \multicolumn{10}{|l|}{ Alcohol use } \\
\hline Non-drinker & $15(38.5)$ & $132(29.1)$ & 0.185 & $11(45.8)$ & 135 (28.9) & 0.079 & $17(32.6)$ & $130(29.6)$ & 0.59 \\
\hline Low/High risk drinker & $23(60)$ & $320(70.6)$ & & $13(54.2)$ & $330(70.6)$ & & $34(65.4)$ & $308(70.2)$ & \\
\hline \multicolumn{10}{|l|}{ Tobacco smoking } \\
\hline Current smoker & $2(5.1)$ & $20(44.2)$ & 0.836 & $1(4.2)$ & $21(4.5)$ & 0.930 & $4(7.7)$ & $18(4.1)$ & 0.236 \\
\hline Non-smoker & $37(94.9)$ & $433(95.6)$ & & $23(95.8)$ & $446(95.5)$ & & $48(92.3)$ & $421(95.9)$ & \\
\hline \multicolumn{10}{|l|}{ Illicit drug use } \\
\hline Yes & $27(69.2)$ & $291(64.2)$ & 0.531 & $17(70.8)$ & $300(64.2)$ & 0.510 & $37(71.2)$ & $281(64)$ & 0.308 \\
\hline No & $12(30.8)$ & $162(35.8)$ & & $7(29.2)$ & $167(35.8)$ & & $15(28.8)$ & $158(36)$ & \\
\hline \multicolumn{10}{|c|}{ Depressive symptoms (CES-D 10) } \\
\hline$<10$ & $7(17.9)$ & $358(79)$ & $<0.001$ & $4(16.7)$ & $361(77.3)$ & $<0.001$ & $24(46.2)$ & $341(77.7)$ & $<0.001$ \\
\hline$\geq 10$ & $32(82.1)$ & $90(21)$ & & $20(83.3)$ & $101(21.7)$ & & $27(51.2)$ & $95(21.6)$ & \\
\hline \multicolumn{10}{|c|}{ Depression in the past 3 years ( Previous Mental health) } \\
\hline Yes & $13(33.3)$ & $45(10.1)$ & $<0.001$ & $5(20.8)$ & $53(11.5)$ & 0.172 & $13(25)$ & $45(10.4)$ & 0.002 \\
\hline No & $26(66.7)$ & $400(89.9)$ & & $19(71.2)$ & $406(88.5)$ & & $39(75)$ & $386(89.6)$ & \\
\hline \multicolumn{10}{|c|}{ Anxiety symptoms (GAD) } \\
\hline$<6$ & $15(38.5)$ & $374(82.6)$ & $<0.001$ & $5(20.8)$ & $384(82.2)$ & $<0.001$ & $32(61.5)$ & $356(81.1)$ & 0.001 \\
\hline$\geq 6$ & $24(61.5)$ & $79(17.4)$ & & $19(79.2)$ & $83(17.8)$ & & $20(38.5)$ & $83(18.9)$ & \\
\hline \multicolumn{10}{|c|}{ Anxiety in the past 3 years (Previous Mental health) } \\
\hline Yes & $6(15.4)$ & $26(5.8)$ & 0.021 & $4(16.7)$ & $28(6.1)$ & 0.042 & $8(15.4)$ & $24(5.6)$ & 0.007 \\
\hline No & $33(84.6)$ & $419(94.2)$ & & $20(83.3)$ & $431(93.9)$ & & $44(84.6)$ & $407(94.4)$ & \\
\hline \multicolumn{10}{|l|}{ Stress } \\
\hline $\begin{array}{l}\text { Not at all/somewhat } \\
\text { stressed }\end{array}$ & $22(56.4)$ & $396(87.4)$ & $<0.001$ & $10(41.7)$ & $407(87.2)$ & $<0.001$ & $37(71.2)$ & $380(86.6)$ & 0.002 \\
\hline $\begin{array}{l}\text { Moderately/very } \\
\text { stressed }\end{array}$ & $17(43.6)$ & $55(12.1)$ & & 14 (58.3) & $58(12.8)$ & & 15 (28.8) & $57(13.4)$ & \\
\hline
\end{tabular}

p-value was based on chi-square test statistics

were more likely to receive low emotional support. Pregnant women with depressive symptoms (AOR=5.3; 95\% CI: 1.59, 17.99; $\mathrm{p}=0.007$ ), anxiety symptoms (AOR: 6.9; 95\% CI: 2.21, 22.11; $\mathrm{p}=0.001)$ and moderately/very stressed (AOR: 3; 95\% CI: 1.17, 7.89; $\mathrm{p}=0.023$ ) were more likely to receive low affectionate support compared with their counterpart. Further, pregnant women who find it difficult all the time/impossible to manage on their available income $(A O R=3 ; 95 \% \mathrm{CI}: 1.29,6.95 ; \mathrm{p}=0.010)$ and those with depressive symptoms $(\mathrm{AOR}=2.8 ; 95 \% \mathrm{CI}$ : $1.48,5.34$; $\mathrm{p}=0.002$ ) are around three times more likely to receive low tangible support.

\section{Discussion}

This study is the first to determine the magnitude and determinants of low social support during pregnancy among Australian women. The overall prevalence of low social support among pregnant women was $7.1 \%$. The primary risk factors identified across the domains of low social support (i.e. low emotional, low affectionate and low tangible supports) were pregnant women's marital status, ability to manage available income, and mental health issues.

The current study found that those pregnant women who were not partnered were 4.4 times more likely to receive low emotional support, compared with partnered pregnant women. Marital Partner is one of the important sources of emotional and affectionate support [49] and support from spouse and marital stability are an important protective factor for the mental well-being of women during pregnancy [50]. Individual studies revealed that lack of support from a companion was more common among those who were not partnered $[51,52]$. Also, compared with non-partnered women, partnered women generally have numerous psychological and social advantages, though much of this may be limited to individuals 
Table 4 Determinants of domains of social support during pregnancy among Australian women ( $n=493$ ), as determined by backward stepwise elimination approach using Multiple logistic regression modelling

\begin{tabular}{|c|c|c|c|c|c|c|}
\hline \multirow[t]{2}{*}{ Variables } & \multicolumn{2}{|c|}{ Emotional support } & \multicolumn{2}{|c|}{ Affectionate support } & \multicolumn{2}{|c|}{ Tangible support } \\
\hline & AOR $(95 \% \mathrm{Cl})$ & p-value & AOR $(95 \% \mathrm{CI})$ & $\mathrm{p}$-value & AOR $(95 \% \mathrm{CI})$ & p-value \\
\hline \multicolumn{7}{|l|}{ Marital status } \\
\hline Partnered & 1.00 & & 1.00 & & 1.00 & \\
\hline Non-partnered & $4.4(1.27,14.99)$ & 0.019 & $4.1(1.004,17.15)$ & 0.053 & $2.5(0.90,7.08)$ & 0.077 \\
\hline \multicolumn{7}{|l|}{ Able to manage on income available } \\
\hline Impossible/difficult all of the time & $3.1(1.18,8.32)$ & 0.023 & - & - & $3(1.29,6.95)$ & 0.010 \\
\hline Difficult some of the time & $1.2(0.48,3.11)$ & 0.669 & - & - & $1.3(0.63,2.72)$ & 0.479 \\
\hline It is easy/not too bad & 1.00 & & & & 1.00 & \\
\hline \multicolumn{7}{|l|}{ Depressive symptoms (CES-D 10) } \\
\hline$<10$ & 1.00 & & 1.00 & & 1.00 & \\
\hline$\geq 10$ & $8.5(3.29,22.27)$ & $<0.001$ & $5.3(1.59,17.99)$ & 0.007 & $2.8(1.48,5.34)$ & 0.002 \\
\hline \multicolumn{7}{|l|}{ Anxiety symptoms (GAD) } \\
\hline$<6$ & 1.00 & & 1.00 & & - & \\
\hline$\geq 6$ & $2.9(1.26,7.03)$ & 0.013 & $6.9(2.21,22.11)$ & 0.001 & - & - \\
\hline \multicolumn{7}{|c|}{ Depression in the past 3 years (previous Mental health) } \\
\hline Yes & & - & - & - & $2(0.94,4.34)$ & 0.073 \\
\hline No & & - & - & & 1 & \\
\hline \multicolumn{7}{|l|}{ Stress } \\
\hline Not at all/somewhat stressed & - & & 1.00 & & - & \\
\hline Moderately/very stressed & - & - & $3(1.17,7.89)$ & 0.023 & - & - \\
\hline
\end{tabular}

For low emotional support: variables entered in step 1; Residence, Marital status, highest qualification, able to manage on income available, current depressive symptoms (CESD- 10), current anxiety symptoms (GAD), Depression in the past 3 years, Anxiety in the past 3 years, Stress. P-value of Hosmer and Lemeshow test $=0.939$

For low affectionate support: variables entered in step 1; Marital status, highest qualification, able to manage on income available, alcohol use, current depressive symptoms (CESD- 10), current anxiety symptoms (GAD), Depression in the past 3 years, Anxiety in the past 3 years, Stress. P-value of Hosmer and Lemeshow test $=0.287$

For low tangible support: variables entered in step 1; Marital status, highest qualification, able to manage on income available, pregnancy months, Tobacco smoking, current depressive symptoms (CESD- 10), current anxiety symptoms (GAD), Depression in the past 3 years, Anxiety in the past 3 years, Stress. P-value of Hosmer and Lemeshow test $=0.965$

Cl Confidence interval, AOR Adjusted Odds Ratio, CES-D 10 Center for Epidemiological Studies Depression scale, GAD Goldberg Anxiety and Depression scale

living in a satisfactory marital relationship [53] because pregnant women living in a violent relationship with their partner are more likely to receive less social support [54]. Our finding is supported by previous studies conducted in US [55], Sweden [51] and Portugal [52]. However, cross-sectional study conducted in Iran $(\mathrm{n}=320)$ [56] and Southern Brazil $(n=871)$ [31] among a sample of pregnant women reported that marital status has no significant association with social support. The possible reason for this inconsistency might be due to the difference in the social support tool used, the demographic characteristics of participants, and the variation in the understanding of social support across individual participant because of the difference in socio-economic settings and cultural variation across countries. For instance, the study conducted in Iran includes participants with age $\geq 18$ years (mean age $25.7 \pm 5.5$ years) and used a 23 item Vaux Social Support Questionnaire with three domains (support from family, friends and relatives), whereas our study includes participants with the age range of 34 to 39 years (mean age $36.3 \pm 1.42$ years) and used 19 item MOSS scale which examined the emotional/informational support, affectionate support/ positive social interaction and tangible support. Additionally, the non-significance of marital status in a study conducted in Iran might be due to small number of nonpartnered pregnant women $(\mathrm{n}=1)$ which can limit the power of the analysis.

Our study shows that pregnant women who have difficulty in managing available income are three times more likely to receive low emotional and/or low tangible support compared to those women who receive high emotional and/or high tangible support. This concept was supported by a study conducted in Germany, which identified that socially disadvantaged persons more often report poor social networks and social support compared 
with their counterpart [57]. Also, pregnant women with a higher household income predict better perceived social support based on reports of a study conducted in Mexico [58]. It is argued that individuals living in low socioeconomical class tend to have a more limited relational radius and prefer self-isolation from the social events because involvement in social activities needs money to afford events which might lead them to self-neglect from the society [59]. Moreover, withdrawal from society and having less friends may lead them to the feeling of loneliness, receive low emotional support and/or low affectionate support from the social environment including family, friends and spouse [60].

Our study identifies depression during pregnancy as positively associated with the three domains of social support (i.e. low emotional/informational support, low affectionate/positive social interaction and low tangible support). The possible reason could be, individuals with depression tend to withdraw themselves from social support and thus communicate with fewer family member/friends or they might feel more mistrustful and underestimate the level of existing support [61]. Also, in the current study, participants were asked to report if they experienced depressive symptoms in the past week before the day of filling the questionnaire. Therefore, past week depressive symptoms could be strongly associated with low social support because being depressed may affect the perception of social support which might lead to underestimating the support received [62]. Besides, depressed individuals induce negative responses and create interpersonal difficulties in their interactions with others, which can lead to avoidance or rejection by others $[61,63,64]$. The interpersonal accounts of depression also suggest that negative self-evaluation and social inadequacy manifested by depressed individuals disrupt social interactions $[65,66]$ and as a result, an individual could be at risk of receiving low social support from family, friends and community. The finding in the current study supported by a cross-sectional study conducted in Iran among pregnant women $(\mathrm{n}=320)$, which revealed a significant inverse relationship between depression and total social support score $(\mathrm{p}<0.001)$, family support $(\mathrm{p}<0.001)$, friends support $(<0.001)$ and relative's support $(\mathrm{p}=0.003)[56]$.

Our study shows pregnant women who have anxiety symptoms are almost three and nine times more likely to receive low emotional and low affectionate support respectively, as compared to those without anxiety symptoms. It is known that anxiety impairs social interaction [31], which explains why individuals with this disorder tend to be lonely and did not have the need to communicate. However, it is also possible that individuals who have anxiety symptoms are mainly involved by their own concerns and did not acknowledge the support received [67]. The finding of our study supported by, a crosssectional study conducted in Southern Brazil $(n=871)$ which found a moderate association between anxiety and affectionate, emotional, tangible, and informational domains; and a strong association with the positive social interaction domain [31]. Additional support for our findings comes from, another cross-sectional study conducted in Iran among pregnant women $(n=320)$ which found a significant inverse relationship between antenatal anxiety and total social support score $(\mathrm{p}<0.001)$, family support $(\mathrm{p}<0.001)$, and friends support $(<0.001)[56]$.

Being moderately/very stressed during pregnancy is significantly associated with low affectionate support, as shown in our study. The possible reason for this might be, people with high levels of stress may be less able to keep contact and form a strong social relationship with other people; thus, keeping others in distance probably because they have a fear that they might convey their high stress to their social networks [68]. It is also possible that people with high levels of perceived stress underestimate the social support they receive and did not use support in a way that could benefit their psychological well-being [69].

Some limitations need to be considered when interpreting our study findings. First, the findings rely on selfreported data from study participants and therefore are prone to recall bias. Second, our findings are limited to pregnant women within the age range of 34-39 years (i.e. younger pregnant women not included) and this was because of undertaking a secondary analysis of a preexisting database. Third, our study didn't assess the social class of study participants, as a result, we couldn't stratify the marital status of study participants with their corresponding social class to see if it has an effect on marital status in predicting domains of social support. Fourth, the use of a cross-sectional study design in the study raises concerns about reverse causation between low social support and depressive and/or anxiety symptoms. The cross-sectional study design cannot ensure the necessary time-based order of events. Specifically, if low social support (i.e. the exposure variable) precedes, it may cause individuals to develop depressive and/or anxiety symptoms (i.e. the outcome variable). In contrast, the early presence of depressive and/or anxiety symptoms may cause an individual to receive low social support. Therefore, reverse causation is possible, which creates a vicious circle that cannot be accurately modelled in a cross-sectional design. However, analyzing data collected from a nationally representative sample of pregnant women is the strength of our study.

Overall, the current study offers evidence of sociodemographic, psychosocial and lifestyle behavioural determinants of low social support, and a better understanding 
of these risk factors will allow for more targeted screening to identify pregnant women who are at risk of receiving low social support. Further research identifying the experience and details of additional risk factors for low social support amongst pregnant women is needed to help inform intervention strategies to improve the physical and psychological well-being of Australian pregnant women. Finally, to address the issue of reverse causation in the associations between low social support and depressive and/or anxiety symptoms, future longitudinal studies, which can ensure the temporal order of event, particularly over the different stages of pregnancy is strongly recommended.

\section{Conclusions}

Seven Percent of pregnant women in Australia reported low social support during their pregnancy. Having a mental health problems (depressive and/or anxiety symptoms), experiencing stress, being at a low socio-economic status, and not being in a marital relationship are all significant determinants of low social support. Maternal health professionals can use this information to screen pregnant women at risk of receiving low social support as well as develop policy to help enhance the social support being given and the psychological wellbeing being of pregnant women.

\begin{abstract}
Abbreviations
ALSWH: Australian Longitudinal Study on Women's Health; AOR: Adjusted odds ratio; BAl: Beck Anxiety Inventory; CES-D-10: 10 Item Center for Epidemiological Study Depression scale; Cl: Confidence interval; C/S: Cesarean section; DUSOCS: Duke Social Support and Stress Scale; EPDS: Edinburgh Postnatal Depression Scale; GADS: Goldberg Anxiety Depression Scale; GP: General prac titioner; LMICs: Low and middle income countries; LOT-R: Life Orientation Test Revised; MOS-SSS-19: 19 Item Medical Outcome Study Social Support Scale; STAI: State-Trait Anxiety Inventory; WHO: World Health Organization.
\end{abstract}

\section{Acknowledgements}

The research on which this paper is based was conducted as part of the Australian Longitudinal Study on Women's Health, the University of Newcastle and the University of Queensland. We would like to acknowledge the Australian Government Department of Health and Ageing for funding and to the women who provided the survey data.

\section{Authors' contributions}

$A B$ and DS conceived the study, planned the study design and performed the analyses. AB performed the report write-up and drafted the manuscript. DS, JA and WP contributed in the analysis, reviewing draft document and manuscript. All authors read and approved the final manuscript.

\section{Funding}

The ALSWH is funded by the Australian Government Department of Health and Ageing. The funding source had no role in the design, data collection, analysis, manuscript write-up; or in the decision to submit the manuscript for publication.

\section{Availability of data and materials}

After request, all analyzed data will be available from the Australian Longitudinal Study on Women's Health (ALSWH). https://www.alswh.org.au/

\section{Declarations}

Ethics approval and consent to participate

The ALSWH has been granted ethics clearance by the human research Ethics committee of the University of Newcastle (\#H-076-0795) and the University of Queensland (\#2004000224). Study participants were involved voluntarily and provided written informed consent. The confidentiality of study participants' information is firmly monitored by ALSWH staff. Approval letter for the current study was obtained from the Human Research Ethics Committee of the University of Technology Sydney (ETH20-5306).

\section{Consent for publication}

Not applicable.

\section{Competing interests}

The authors declare they have no competing interest.

\section{Author details}

${ }^{1}$ College of Medicine and Health Sciences, Faculty of Health, School of Nursing, Hawassa University, Hawassa, Ethiopia. ${ }^{2}$ Australian Centre for Public and Population Health Research, School of Public Health, Faculty of Health, University of Technology Sydney, Ultimo, NSW, Australia.

Received: 17 November 2020 Accepted: 19 July 2021

Published online: 27 July 2021

\section{References}

1. Davalos DB, Yadon CA, Tregellas HC. Untreated prenatal maternal depression and the potential risks to offspring: a review. Arch Womens Ment Health. 2012;15:1-14.

2. Smith MV, Shao L, Howell H, Lin H, Yonkers KA. Perinatal depression and birth outcomes in a Healthy Start project. Matern Child Health J. 2011;15:401-9.

3. Sabroza AR, Leal MC, Souza PR, Gama SGN. Some emotional repercussions of adolescent pregnancy in Rio de Janeiro, Brazil (1999-2001). Cadernos de saude publica. 2004;20:S130-7.

4. Brown SJ, Yelland JS, Sutherland GA, Baghurst PA, Robinson JS. Stressful life events, social health issues and low birthweight in an Australian population-based birth cohort: challenges and opportunities in antenatal care. BMC Public Health. 2011;11:196.

5. Diego MA, Jones NA, Field T, Hernandez-Reif M, Schanberg S, Kuhn C, Gonzalez-Garcia A. Maternal psychological distress, prenatal cortisol, and fetal weight. Psychosom Med. 2006;68:747-53.

6. Divney AA, Sipsma H, Gordon D, Niccolai L, Magriples U, Kershaw T. Depression during pregnancy among young couples: the effect of personal and partner experiences of stressors and the buffering effects of social relationships. J Pediatr Adolesc Gynecol. 2012;25:201-7.

7. Da Costa D, Larouche J, Dritsa M, Brender W. Psychosocial correlates of prepartum and postpartum depressed mood. J Affect Disord. 2000;59:31-40.

8. Cohen MM, Ansara D, Schei B, Stuckless N, Stewart DE. Posttraumatic stress disorder after pregnancy, labor, and delivery. J Women's Health. 2004:13:315-24.

9. Hupcey JE. Clarifying the social support theory-research linkage. J Adv Nurs. 1998:27:1231-41.

10. Dunkel Schetter C. Psychological science on pregnancy: stress processes, biopsychosocial models, and emerging research issues. Annu Rev Psychol. 2011;62:531-58.

11. Orr ST, Miller CA. Unintended pregnancy and the psychosocial well-being of pregnant women. Womens Health Issues. 1997;7:38-46.

12. Cohen S, Wills TA. Stress, social support, and the buffering hypothesis. Psychol Bull. 1985;98:310.

13. Feldman PJ, Dunkel-Schetter C, Sandman CA, Wadhwa PD. Maternal social support predicts birth weight and fetal growth in human pregnancy. Psychosom Med. 2000;62:715-25.

14. Cohen S, Underwood LG, Gottlieb BH. Social support measurement and intervention: a guide for health and social scientists. Oxford: Oxford University Press; 2000. 
15. Giesbrecht GF, Poole JC, Letourneau N, Campbell T, Kaplan BJ, Team AS. The buffering effect of social support on hypothalamic-pituitary-adrenal axis function during pregnancy. Psychosom Med. 2013;75:856-62.

16. Rini C, Schetter CD, Hobel CJ, Glynn LM, Sandman CA. Effective social support: Antecedents and consequences of partner support during pregnancy. Pers Relat. 2006;13:207-29.

17. Da Costa D, Dritsa M, Rippen N, et al. Health-related quality of life in postpartum depressed women. Arch Womens Ment Health. 2006;9:95-102.

18. Robertson E, Grace S, Wallington T, et al. Antenatal risk factors for postpartum depression: a synthesis of recent literature. Gen Hosp Psychiatry. 2004;26:289-95.

19. Zachariah R. Social support, life stress, and anxiety as predictors of pregnancy complications in low-income women. Res Nurs Health. 2009;32:391-404

20. Glazier RH, Elgar FJ, Goel V, Holzapfel S. Stress, social support, and emotional distress in a community sample of pregnant women. J Psychosom Obstet Gynecol. 2009;25:247-55.

21. Solar O, Irwin A: A conceptual framework for action on the social determinants of health. 2007.

22. Landman-Peeters KM, Hartman CA, van der Pompe G, den Boer JA, Minderaa RB, Ormel J. Gender differences in the relation between social support, problems in parent-offspring communication, and depression and anxiety. Soc Sci Med. 2005;60:2549-59.

23. Orr ST. Social support and pregnancy outcome: a review of the literature. Clin Obstet Gynecol. 2004;47:842-55.

24. Morikawa M, Okada T, Ando M, Aleksic B, Kunimoto S, Nakamura Y, Kubota C, Uno Y, Tamaji A, Hayakawa N, et al. Relationship between social support during pregnancy and postpartum depressive state: a prospective cohort study. Sci Rep. 2015;5:10520.

25. Spoozak L, Gotman N, Smith MV, Belanger K, Yonkers KA. Evaluation of a social support measure that may indicate risk of depression during pregnancy. J Affect Disord. 2009;114:216-23.

26. Werner E, Miller M, Osborne LM, Kuzava S, Monk C. Preventing postpartum depression: review and recommendations. Arch Womens Ment Health. 2015;18:41-60.

27. Mutale T, Creed F, Maresh M. Hunt L: Life events and low birthweightanalysis by infants preterm and small for gestational age. Br J Obstet Gynaecol. 1991;98:166-72.

28. Degen HM, Myers BJ, Williams-Petersen MG, Knisely JS, Schnoll SS. Social support and anxiety in pregnant drug abusers and nonusers: unexpected findings of few differences. Drug Alcohol Depend. 1993;32:37-44.

29. Dunnagan T, Haynes G, Christopher S, Leonardson G. Formative evaluation of a multisite alcohol consumption intervention in pregnant women. Neurotoxicol Teratol. 2003;25:745-55.

30. Shishehgar S, Mahmoodi A, Dolatian M, Mahmoodi Z, Bakhtiary M, Alavi Majd $H$. The relationship of social support and quality of life with the level of stress in pregnant women using the PATH model. Iran Red Crescent Med J. 2013;15:560-5.

31. Peter PJ, de Mola CL, de Matos MB, Coelho FM, Pinheiro KA, da Silva RA, Castelli RD, Pinheiro RT, Quevedo LA. Association between perceived social support and anxiety in pregnant adolescents. Braz J Psychiatry. 2017;39:21-7

32. Emmanuel EN, Creedy DK, St John W, Brown C. Maternal role development: the impact of maternal distress and social support following childbirth. Midwifery. 2011;27:265-72.

33. Brown WJ, Bryson L, Byles JE, Dobson AJ, Lee C, Mishra G, Schofield M. Women's Health Australia: recruitment for a national longitudinal cohort study. Women Health. 1999;28:23-40.

34. Loxton D, Tooth L, Harris ML, Forder PM, Dobson A, Powers J, Brown W, Byles J, Mishra G. Cohort profile: the Australian longitudinal study on Women's health (ALSWH) 1989-95 cohort. Int J Epidemiol. 2018;47:391-392e.

35. Lee C, Dobson AJ, Brown WJ, Bryson L, Byles J, Warner-Smith P, Young AF. Cohort profile: the Australian longitudinal study on women's health. Int J Epidemiol. 2005;34:987-91.

36. Sherbourne CD, Stewart AL. The MOS social support survey. Soc Sci Med. 1991;32:705-14.

37. Department of Health and Aged Care (GISCA). Measuring remoteness: Accessibility/Remoteness Index of Australia (ARIA), Revised Ed. Canberra: Department of Health and Aged Care; 2001.
38. Bell S, Lee C. Development of the perceived stress questionnaire for young women. Psychol Health Med. 2002;7:189-201.

39. Bell S, Lee C. Perceived stress revisited: the Women's Health Australia project young cohort. Psychol Health Med. 2003;8:343-53.

40. Bell S, Lee C. Does timing and sequencing of transitions to adulthood make a difference? Stress, smoking, and physical activity among young Australian women. Int J Behav Med. 2006;13:265-74.

41. Andresen EM, Malmgren JA, Carter WB, Patrick DL. Screening for depression in well older adults: evaluation of a short form of the CES-D (Center for Epidemiologic Studies Depression Scale). Am J Prev Med. 1994;10:77-84

42. Canady RB, Stommel M, Holzman C. Measurement properties of the centers for epidemiological studies depression scale (CES-D) in a sample of African American and non-Hispanic White pregnant women. J Nurs Meas. 2009;17:91-104.

43. Mosack V, Shore ER. Screening for depression among pregnant and postpartum women. J Community Health Nurs. 2006;23:37-47.

44. Marcus SM, Flynn HA, Blow FC, Barry KL. Depressive symptoms among pregnant women screened in obstetrics settings. J Womens Health. 2003;12:373-80.

45. Holzman C, Eyster J, Tiedje LB, Roman LA, Seagull E, Rahbar MH. A life course perspective on depressive symptoms in mid-pregnancy. Matern Child Health J. 2006;10:127.

46. Seto M, Cornelius MD, Goldschmidt L, Morimoto K, Day NL. Long-term effects of chronic depressive symptoms among low-income childrearing mothers. Matern Child Health J. 2005;9:263-71.

47. Goldberg D, Bridges K, Duncan-Jones P, Grayson D. Detecting anxiety and depression in general medical settings. BMJ. 1988;297:897-9.

48. Hosmer DW, Lemeshow S. Applied Logistic Regression. New York: Wiley; 2000.

49. Eaton WW. Life events, social supports, and psychiatric symptoms: A re-analysis of the New Haven data. J Health Soc Beh. 1978;1:230-4.

50. Freitas G, Botega NJ. Prevalence of depression, anxiety and suicide ideation in pregnant adolescents. Rev Assoc Med Bras. 1992;2002(48):245-9.

51. Wahn EH, Nissen E. Sociodemographic background, lifestyle and psychosocial conditions of Swedish teenage mothers and their perception of health and social support during pregnancy and childbirth. Scand J Public Health. 2008;36:415-23.

52. Figueiredo B, Bifulco A, Pacheco A, Costa R, Magarinho R. Teenage pregnancy, attachment style, and depression: a comparison of teenage and adult pregnant women in a Portuguese series. Attach Hum Dev. 2006;8:123-38

53. Kaplan G, DeLongis A: Psychosocial factors influencing the course of arthritis: A prospective study. In annual meeting of the American Psychological Association, Anaheim, CA. 1983: 3-21.

54. Hamberger LK, Arnold J. The impact of mandatory arrest on domestic violence perpetrator counseling services. Family Violence Bulletin. 1990;6:10-2.

55. Cohen K, Capponi S, Nyamukapa M, Baxter JK, Worly BL. Social determinants of partner support in pregnancy. Obstet Gynecol. 2014;123:142S.

56. Rafiei N, Amini Rarani M, Eizadi F, Rafiey H, Seyedghasemi NS. Social support and its role in the prevention of depression and anxiety during pregnancy in Turkmen women. Int J Biomed Public Health. 2019:2:75-80.

57. Weyers S, Dragano N, Möbus S, Beck E-M, Stang A, Möhlenkamp S, Jöckel $\mathrm{KH}$, Erbel R, Siegrist J. Low socio-economic position is associated with poor social networks and social support: results from the Heinz Nixdorf Recall Study. Int J Equity Health. 2008;7:13.

58. Sciarra DT, Ponterotto JG. Adolescent motherhood among low-income urban Hispanics: familial considerations of mother-daughter dyads. Qual Health Res. 1998:8:751-63.

59. Bourdieu P: The Fine Distinctions (in German) Frankfurt am Main. Suhrkamp; 1982.

60. Nobis T, El-Kayed N. Social inequality and sport in Germany-a multidimensional and intersectional perspective. Eur J Sport Soc. 2019;16:5-26.

61. Ibarra-Rovillard MS, Kuiper NA. Social support and social negativity findings in depression: perceived responsiveness to basic psychological needs. Clin Psychol Rev. 2011;31:342-52. 
62. Gariepy G, Honkaniemi H, Quesnel-Vallee A. Social support and protection from depression: systematic review of current findings in Western countries. Br J Psychiatry. 2016;209:284-93.

63. Stice E, Ragan J, Randall P. Prospective relations between social support and depression: differential direction of effects for parent and peer support? J Abnorm Psychol. 2004;113:155.

64. Oxman TE, Hull JG. Social support, depression, and activities of daily living in older heart surgery patients. J Gerontol B Psychol Sci Soc Sci. 1997:52:P1-14.

65. Rudolph KD, Flynn M, Abaied JL: A developmental perspective on interpersonal theories of youth depression. 2008.

66. Joiner Jr TE: Depression in its interpersonal context. 2002.

67. Falcone EMO, Baptista MN, Placido MG, Krieger S, Oliveira ER, Falcone JF, Vieira BFL. Construction and content validity of the Anxiety Cognitive Scale in adults. Psicologia em Pesquisa. 2016;10:85-93.
68. Coyne JC, Downey G. Social factors and psychopathology: Stress, social support, and coping processes. Annu Rev Psychol. 1991;42:401-25.

69. Ioannou M, Kassianos AP, Symeou M: Coping with depressive symptoms in young adults: perceived social support protects against depressive symptoms only under moderate levels of stress. Front Psychol 2019, 9: 1.

\section{Publisher's Note}

Springer Nature remains neutral with regard to jurisdictional claims in published maps and institutional affiliations.
Ready to submit your research? Choose BMC and benefit from:

- fast, convenient online submission

- thorough peer review by experienced researchers in your field

- rapid publication on acceptance

- support for research data, including large and complex data types

- gold Open Access which fosters wider collaboration and increased citations

- maximum visibility for your research: over $100 \mathrm{M}$ website views per year

At BMC, research is always in progress.

Learn more biomedcentral.com/submissions 